Portland State University

PDXScholar

\title{
A Literature Review on Police Encounters with Women
}

Cecilia I. Hinsley

Portland State University

Follow this and additional works at: https://pdxscholar.library.pdx.edu/honorstheses

Part of the Criminology and Criminal Justice Commons Let us know how access to this document benefits you.

\section{Recommended Citation}

Hinsley, Cecilia I., "A Literature Review on Police Encounters with Women" (2020). University Honors Theses. Paper 811.

https://doi.org/10.15760/honors.830

This Thesis is brought to you for free and open access. It has been accepted for inclusion in University Honors Theses by an authorized administrator of PDXScholar. Please contact us if we can make this document more accessible: pdxscholar@pdx.edu. 
A Literature Review on Police Encounters with Women

\section{by}

Cecilia Hinsley

An undergraduate honors thesis submitted in partial fulfillment of the

requirements for the degree of

Bachelor of Arts

in

University Honors

and

Criminology and Criminal Justice

Thesis Adviser

Mark Harmon Leymon

Portland State University

2020 
HONORS THESIS 
Honors Thesis

Abstract: This study is a literature review on current research surrounding police officers and their encounters with women. This paper explores research and work that speaks to how police officers might support women and/or work with women in various communities towards a common goal such as crime prevention. Twenty articles considering police encounters with women were gathered and reviewed to identify the implications of future contact and police behaviors with women in society. Based on the articles reviewed, they suggest that current policing styles such as, community-oriented policing and problem-oriented policing, have a positive impact on women in society and their children (Giacomazzi \& Smithey 2001). 
Research question: The topic of study is focused on interactions between women and police officers. More specifically, are the interactions between the two groups positive or negative? What kinds of support do police officers offer to females in society? How does community-oriented policing and similar policing models influence or change the support and/or relationship between the two? What impact do the different policing styles have on women in society? Are there some parts of the interaction between police and women in the community that can be better explored? Will others take time to analyze the problem further and develop another strategy to prevent women from entering the criminal justice system? This literature review strives to provide direction for future policing models and additional evaluative research in criminology and criminal justice. The aforementioned research questions are focused on during the review of police officer encounters below.

Introduction: Community-Policing can be defined as a policing style that recognizes the lives of individuals and makes efforts to solve the issues of communities (Giacomazzi \& Smithey 2001). This strategy is a partnership between communities and policing agencies. Not only can the police enforce laws, but they can address crimes, crime victims and a variety of issues within specific communities. They can bring the community together on efforts of preventing and reporting crime (Giacomazzi \& Smithey, 2001, p.101). An example of this could simply be the police actively going out and educating citizens on certain crime issues around neighborhoods and educating on the fear of specific crimes. The police can also actively involve business owners, residents, and local agencies in approaches to reduce crimes in a certain area of a neighborhood or city (Giacomazzi \& Smithey, 2001, p.101-102).

Another important policing strategy to consider is Problem-oriented policing or POP. This policing strategy was first developed by a man named Herman Goldstein in 1979 (Problem-Oriented Policing, n.d.). This policing strategy was developed to approach crime in a more proactive manner than previous policing models (Problem-Oriented Policing, n.d.). Problem-oriented policing enables police to focus on a specific problem in a community, analyze the problem and develop a strategy for it, and then 
evaluate the impact that their strategy has on the problem (Problem-Oriented Policing, n.d.). POP focuses on more than just the crime, it goes deeper into why the crime is happening and attempts to understand the root cause of the crime to prevent it from recurring. For example, officers focusing on why there are large amounts of heroin in certain neighborhoods versus trying to arrest anyone they can find possessing or using the drug is an example of the POP approach to policing (n.d.). Retrieved from https://www.youtube.com/watch?v=wK8gIFZuQw8. Another example can be seen with prostitution. Officers can arrest people for prostitution and create stings to catch offenders. However, the POP approach to prostitution would be going out and asking prostitutes why they do what they do and asking yourself what would want to make someone do this kind of work (n.d.). Retrieved from https://www.youtube.com/watch?v=wK8glFZuQw8.

There are disagreements within the literature on the best policing model for police agencies. The discussion within the discourse community around policing styles and their effect on certain groups in society reveals some of these disparities. Giwa describes Community policing as one that lacks data on its effectiveness and as a style unable to be tested for effectiveness. Giwa believes that this model has failed and is nearing an end due to predisposed factors. These factors are things such as the fact that it is uncertain how much influence the public has over policies and practices (Giwa, 2018, p.716). Instead of improving relationships between police and the public, community-oriented policing has focused on improving the image of the police in the eyes of the public. Some researchers argue that if communityoriented policing is lost, women and children victims will lose rights and be criminally exploited more than they currently are (Murray, 2006, p.132).

On the contrary, Giwa describes Community policing as a "failed promise" (Giwa, 2018, p.710). Giwa explains how community policing programs such as (COMPAC), a community policing program with Ottawa's community in Canada and the Police Action Committee, have been around for as long as 17 years and have yet to bridge relationships between officers and racialized neighborhoods (Giwa, 
2018, p.717). Operational challenges in community policing have been found in neighborhood watch community programs (Giwa, 2018, p.717). Neighborhoods with racialized and minority members that are more collectivistic tend to be unwilling to work with police from beginning. Therefore, participation in these programs can be minimal and unsuccessful in heavily racialized neighborhoods that police are aiming to improve relations due to preexisting tension.

Methodology: Twenty articles were selected from the Criminal Justice Abstracts with Full Text database off the Portland State University Library website. This database was selected because it offers complete texts, citations and references of scholarly work surrounding the research topic. This database also includes relevant subjects such as policing, deterrence, crime patterns, sentencing, and more. Articles from no earlier than 1979 were selected because that is when POP came into play in the criminal justice system in the United States. It is important to include studies that focus on the POP policing style and similar ones. The POP policing style is one that strives to bridge the gap between the police and the community they serve. Especially with minority groups, underrepresented groups such as women and/or victims of repeated crimes. Research relevant to my topic includes those that are trying to make connections between officers and communities. There is more focus now on repairing relationships between communities and police. Preventing crime and figuring out the root causes of crime is now on the forefront of criminologists' minds and many more (Jackson, 2016). An additional focus will be placed on articles from the late 1990's and later to find more recent scholarly works for relevance on the topic. The following keywords and phrases were used in searches for articles: POLICE INTERACTIONS, POLICE LEGITIMACY, PROCEDURAL JUSTICE, WOMEN, FEMALES and POLICING.

\section{$\underline{\text { Literature Review }}$}

The first five articles discussed below include:

Miller, S. L. (1998). Rocking the rank and file: Gender issues and community policing. Coulter, M. L., Kuehnle, K., Byers, R., \& Alfonso, M. (1999). Police-Reporting Behavior and Victim-Police Interactions as 
Described by Women in a Domestic Violence Shelter. Sims, B., Scarborough, K. E., \& Ahmad, J. (2003). The relationship between police officers' attitudes toward women and perceptions of police models. DeJong, C. (2005). Gender differences in officer attitude and behavior. Murray, J. (2006). Criminal exploitation of women and children and the important role of community policing.

The first five articles reviewed have publishing dates from 1999 to 2006. The first article by Miller explores officer gender in community policing. Miller discusses gender-role stereotypes of male and female officers. He describes how community policing welcomes women officers' natural traits and abilities around compassion, peacemaking, negotiation, cooperation, empathy, communication, etc. He believes that the core of community policing is better communication between police officers and the residents of communities. Miller calls for additional research on how "...gender and gender role expectations shape police evaluation practices" (Miller, 1998, p.167). Miller states that there is a "conflict between traditional beliefs and alternative beliefs" (Miller, 1998, p.166). He argues that in order to successfully move from a traditional para militaristic policing style into a new community-oriented style, skill must not be gendered.

In Coulter et. al, the research focus is to analyze "...the relationship between abuse characteristics and calls to the police" (Coulter, Kuehnle, Byers \& Alfonso, 1999, p.1291). The authors examine victims' perceptions on the responses of police officers "to their calls for help" (Coulter, Kuehnle, Byers \& Alfonso, 1999, p.1291). The data includes 500 questionnaires. Includes qualitative and quantitative data. The study was conducted in the largest shelter for domestic violence victims in the state of Florida. The questionnaires were given to women during the intake process at the shelter from June of 1995 to August of 1996. The findings show a significant relationship between abuse type and the victims' decision to call police for help. The type of abuse that elicited a call for help to police was physical abuse. Significance between the victim and their relationship with their abuser was also found. Over $70 \%$ of victims that called police for help, identified the perpetrator of abuse as their current partner. Additionally, significance was 
found in the relationship of the abuser to the victim and whether the abuser was arrested. Generalization of the findings is limited due to self-reporting, sample and sample size. Another weakness might be the timeframe that the data was collected from. Some could argue that it is now outdated due to changes in domestic relationships and policing styles over time. One of the strengths in the study is the mix of both quantitative and qualitative data. The policing style in Florida during that time frame was not identified. Coulter et al argue that "... it is estimated that women, compared to men, are almost twice as likely not to report a crime due to fear of retaliation" (Coulter et al., 1999, p.1,290). Furthermore, they argue that the non-reporting rate is even higher for women who have experienced domestic violence versus nonabused women. The results of their study show that "...almost half the women who entered a battered women's shelter... did not seek help from the police" (Coulter et al., 1999, p.1,290). Due to the results of the study, the authors suggest that further training in responding to domestic violence calls is needed. The authors argue that the lack of training results in subjective responses by police that include their own personal beliefs and values on domestic violence.

In what ways can attitudes towards women predict attitudes towards community-oriented policing? In the article: The relationship between police officers' attitudes toward women and perceptions of police models, the data collected came from surveys given to 560 sworn police officers at Little Rock Police Department in the year 2000. The findings suggest minority officers are more likely to believe that women in the United States still suffer from discrimination. Education had little to no correlation on affecting the attitudes of officers towards community policing. Officer marital status influenced the attitudes towards women in the workplace. Officers that identified as married or in a relationship had more favorable attitudes towards women than single officers. Another finding was that as time spent with female officers increased, the likelihood of having negative attitudes towards women decreased. Limitations on generalizability due to survey research. The scope of the research is only on one agency in Little Rock Arkansas. 
Does citizen sex affect the way different genders of police respond? How do police officer attitudes affect police-citizen encounters? What are the attitudinal differences between male and female officers? Do these differences provide comfort or reassurance to citizens? Ultimately, the article: Gender differences in officer attitude and behavior, focuses on the relationship between officer gender, attitude and behavior. The data used for analysis came from the Project on Policing Neighborhoods (POPN). Observational data was extracted from ride-alongs by trained observers and self-reports from surveys given to officers. The article points out that not all people that police come across are criminals and those perpetrating crime. The author draws attention to the fact that most of the people police officers encounter are victims "...whose satisfaction with such encounters has become a major focus of research on policing" (Dejong, 2005, p.2). Displaying emotion with victimized citizens in contrast to the traditional crime fighter policing image has become increasingly important and focused on by researchers and police administrations (Dejon, 2005, p.2).

However, the findings include: Female citizens were more likely to receive contact and comfort from female officers than males. Both male and female officers were more likely to show comfort to female citizens than male citizens overall. Officer sex interacting with other variables such as education, citizen class, and race had significant effects on behavior. One of the limitations was that POPN was not designed to measure certain behaviors so there are varying explanations for the differences in behaviors measured. The author recognizes that there are differences in organizations and police departments. The author suggests additional research comparing more than just two police departments. Another limitation of the data is that the original study did not measure whether officers felt comfortable engaging in certain behaviors like comfort or coercion with citizens.

In 2006, Murray published an article arguing that if community policing diminishes in practice, then women and children victims will lose more rights and be criminally exploited more than they already are. The criminal exploitation the author covers is human trafficking. The author's concern is 
that if community policing perishes, then the traditional and more paramilitaristic model will fill void (Murray, 2006, p.126-127). The data covered in the article includes Australian Laws and policies on slavery and sexual servitude: Criminal Code Amendment (Slavery and Sexual Servitude) Act. Crimes Act 1914 and the Migration Act 1958. The findings include successful prosecutions for sex crimes and human trafficking rely heavily on information given to the police/investigations.

Information sharing with the police is encouraged within the community policing style. This is not really a finding but a claim that the author makes. The author only describes Australian policy and practices and does not reference any evaluation of those laws. While the points and topics Murray touches on are interesting and important, the author cites himself and his own work often. The scope is limited to human trafficking and sexual servitude in Australia and how the loss of community policing will negatively affect the victims of such crimes.

The next five articles outlined below are: Police-Prostitute Interactions by Williamson et al., Women police: The use of force by and against female officers by Schuck and Rabe-Hemp, Policing domestic violence: Does officer gender matter? by Sun, Female officers and the ethic of care: Does officer gender impact police behaviors? by Rabe-Hemp, and Gender differences in police officers' attitudes: Assessing current empirical evidence by Poteyeva \& Sun.

In Police-Prostitute Interactions, the focus is to reveal what kinds interactions prostitutes and police have had due to the amount of discretion police are given on the job. The authors aim to identify police behaviors when interacting with prostitutes and the implications that those interactions may have for future social work. The data in this article came from three studies on prostitution in the streets from 1998 to 2004 . The first study is comprised of qualitative interviews of ex-prostitutes. The 21 women selected in the first study were found using the snowball technique. The second study included a quantitative survey on police and prostitute interactions. The final and third study was comprised of qualitative interviews of a mix of women; women that were working as prostitutes at the time of the 
interview, women involved in recovery programs, and women not working as prostitutes at the time of the interview and not involved in any type of recovery program. The findings were mixed with a variety in police behavior with prostitutes. Six types of interactions between police and prostitutes were found. The following are the categories of police behavior types: "nice cops, non-responsive officers, police officers as protectors, police officers as perpetrators, cops as a paying customer, and fringe benefit cops" (Williamson et al, 2007, p.22-23). Officer attitudes and demographics were not considered or examined in the study and the authors suggest further studies on those two components.

The qualitative interviews show that police behavior with prostitutes varies and was inconsistent. The authors believe that the behavior inconsistencies depended on two things: First, the police officer's attitude towards prostitution in general. The second; which prostitute they were interacting with. The first kind of officer described by prostitutes was a "nice cop". A nice cop was one that gave advice, a hot beverage or who booked the sex worker for the night so they could rest and get food and shelter. The nonresponsive category of police officers are described as officers that seemed annoyed with sex workers. These officers displayed feelings that sex workers were undeserving of their time and protection and when abused they often made comments to sex workers that they were receiving what they deserved for being a sex worker. Officers as protectors are described by sex workers in the qualitative data also. The protectors were officers that took sex worker complaints seriously, responded to concerns of prostitutes, and even saved their lives sometimes. Then there were officers as perpetrators, officers as paying customers and fringe benefit officers. These officers either verbally or physically assaulted prostitutes, offered payment for services from prostitutes or they used their authority to coerce sex workers into performing sexual acts for them in exchange for their freedom.

The authors suggest the need for additional research on police officer values and beliefs toward women involved in the sex working industry. The authors claim that "Future research is needed to determine the frequency with which women experience the various types of interactions with officers" 
(Williamson, et al., 2007, p.34-35). Williamson et al write they are not surprised "prostituted women do not report assaults or other crimes against them and no not consider police to be a good resource" (Williamson et al, 2007, p.31).

What is the relationship of physical force with citizens by female officers like? The authors in Women police: The use of force by and against female officers, look at force used against female officers and the effects of same sex and mixed sex pairings of officers on force. The authors have four hypotheses. The first is "...that female officers will use less force than their male counterparts" (Schuck \& Rabe-Hemp, 2007, p.96). The second hypothesis is that "...the effect of gender on police use of force should be significant when controlling for other confounding factors" (Schuck \& Rabe-Hemp, 2007, p.96). The third is that there will be lower rates of physical force towards citizens by female officers due to positive attitudes around females as officers (Schuck \& Rabe-Hemp, 2007, p.96). The last hypothesis is that there will be lower levels of physical force used against female officers during domestic calls because women are often seen as better at handling emotions and relations. (Schuck \& Rabe-Hemp, 2007, p.96-97). Surveys were distributed to both male and female officers across six departments. Years the data was gathered: 1996-1997. The sites that the data was collected from: "Charlotte, NC; Colorado Springs, CO; Dallas, TX; St. Petersburg, FL; San Diego Police, CA; and the San Diego Sheriff's Office" There were 7,512 surveys and only $10 \%$ were completed by female officers. The data showed that female officers and female paired officers used less force in citizen interactions than their male counterparts. Female officers were also found to be less likely to use physical force during citizen interactions than male officers. However, citizens used significantly more force towards female officers than male officers during domestic service calls. There are some limitations in the work. The measures of evaluation were limited and there isn't necessarily empirical evidence that female officers are better at de-escalating violent encounters with citizens. The authors suggest an entire study be dedicated to de-escalation techniques and how they compare. 
Do female police officers respond to domestic violence any differently than male officers? Does officer gender matter when responding to domestic violence? Sun addresses these questions in the article Policing domestic violence: Does officer gender matter? Sun argues that there are limited action types by officers included in previous research and there are not very many action types or responses to work with or analyze. Therefore, Sun advocates for "more research efforts should be devoted to the investigation of police supportive actions in handling domestic violence" due to the lack thereof (Sun, 2007, p.582).

The data described in Sun's article comes from the Project on Policing Neighborhoods (POPN) in Indiana and Florida between the summers of (1996 \& 1997). The data is limited to two agencies. However, two approaches were used for analyses; the systematic social observation (SSO) method and collected qualitative data from interviews. Sun seems to favor the SSO method for this topic because it "enables researchers to distinguish police-initiated actions from police responses to citizen requests" (Sun, 2007, p.582). The SSO method observes the object of interest in its natural environment; documenting all events for the entire period of observation (Sun, 2007, p.585). In this study, trained POPN observers used the SSO method with patrol officers during eight-hour shifts. The qualitative data was collected during face-to-face interviews by POPN researchers. Citizens were units of analysis; the sample size was 623 citizens in which 273 were domestic violence incidents. Two types of domestic violence incidents were included: verbal disputes and physical conflicts (Sun, 2007, p.586).

The results showed "The most common supportive action initiated by both female officers and male officers was providing information to citizens" Another common supportive action led by officers was advising citizens to call the police for help if an incident reoccurred. Other supportive actions by officers found were comforting and reassuring citizens and advising them to use the legal system to solve their problems. "In six out of the eight supportive actions, the percentages for female officers were greater than these for male officers, suggesting that female officers are prone to initiate assistance 
to citizens during conflict resolution" (Sun, 2007, p.589). Although referral rates to outside agencies for support were relatively low for both male and female officers, female officers were significantly more likely to ask citizens to seek help from other social services. Female officers were also more likely, compared to male officers, to encourage citizens to call the police if a problem reoccurs. The findings from the project showed that female officers were more likely to provide support to domestic violence situations than male officers. Female and male officers didn't differ in using control actions as well as in the most coercive actions such as arrests. Arrests were not made in most domestic violence responses. In Female officers and the ethic of care: Does officer gender impact police behaviors?, RabeHemp explores how officer gender impacts everyday police-citizen encounters and how it determines what behaviors are used by different genders in encounters and resolutions. Which gender is more likely to use extreme controlling behaviors? Which is more likely to use supporting behaviors? Which gender uses lower level behaviors more often and in what context? The data used for analyses came from the Project on Policing Neighborhoods (POPN). The findings are mixed. They showed that female officers were less likely to use controlling behaviors compared to male officers. However, the findings also showed that female officers were not more likely than male officers to use supporting behaviors. Female officers were 19 percent less likely to use supporting behaviors in police-citizen interactions than males. The research suggests that situational context, citizen demographics, officer demographics, organizational and legal factors also influence officer behaviors (Rape-Hemp, 2008, p.431).

Gender is not the only factor and is not weighed as heavily as one would think. There is a limitation on numerical data for female officers therefore, female officer interactions with citizens are underrepresented in the study. A strength of the study was categorizing police behaviors into meaningful categories making it easier to analyze with the small sample size. The research focuses on data from one study. There is quantitative data extracted from the original study. A weakness is that the data analyzed comes from a study done during the summers of 1996 to 1997. It is hard to confirm that 
the data on behaviors is still relevant if we assume social behaviors and political environments change over time.

What does quantitative data say about how different or similar attitudinal differences are between male and female officers? Poteyeva and Sun focus on analyzing empirical evidence in the article Gender differences in police officers' attitudes: Assessing current empirical evidence, to find the answer to this question. The data explored includes articles between 1990 and 2006 from U.S academic journals only. 27 Journals and 33 articles were extracted from those journals. Only articles that covered studies on U.S. police and police officers' own attitudes. Some of the negatives about the study is that the influence of officer gender on their attitudes of the police role remains inconclusive. The second finding is that there is very little support to show that females would embrace the community policing style better than their male counterparts because of their feminine nature/qualities (Poteyeva \& Sun, 2009, p.516). The third finding is that police attitudes towards the public improved with communityoriented policing. They also found that there is limited support of gender difference in job related stress for officers. One limitation is that qualitative data such as interviews was not covered. Analyses were done on quantitative data only. Another limitation is that only 33 articles over a time period of 17 years was evaluated and does not account for some demographic and organizational changes (Poteyeva \& Sun, 2009, p.520).

The next five articles: Women's Perspectives on the Context of Violence and Role of Police in Their Intimate Partner Violence Arrest Experiences by Li et al, When women tell: Intimate partner violence and the factors related to police notification by Novisky and Peralta, Stereotype threat and racial differences in citizens' experiences of police encounters by Najdowski, Bottoms, \& Goff, Latinas' Perceptions of Law Enforcement: Fear of Deportation, Crime Reporting, and Trust in the System by Messing, Becerra, Ward-Lasher, \& Androff, and Departmental professionalism and its impact on indicators of violence in police-citizen encounters by Shjarback and White. 
In Women's Perspectives on the Context of Violence and Role of Police in Their Intimate Partner Violence Arrest Experiences by Li et al, the researchers' objective is to evaluate women's perspectives and experiences with arrest around intimate partner violence. The study included semi-structured qualitative interviews. Interviews were conducted with women who were court ordered to participate in education programs because of (IPV) intimate partner violence. The women interviewed were women who attended education groups for intimate partner violence from 2009 to 2012 . These women had to be willing to speak freely about their arrest and violent experiences, could be no younger than 18 years old and had to be able to speak English to participate in the study (Li et al, 2015, p.403).

Four themes were found in the reasons why women began using IPV or were a part of IPV. (1) Women's use of violence occurred within a context of their own victimization or trauma experiences (2) the arrest included a complex interplay between subject, partner, and police (3) women perceived police arrest decisions to be based on limited understanding of the context of a dispute and lastly (4) women experienced both positive and negative consequences as a result of their arrest" (Li et al, 2015, p. 406). The first theme describes how women adapted to using violence after being victims of chronic abuse and violence. Several women described being driven to use violence and thus adopted the idea that using violence resembles strength and a means of protecting oneself: "It finally backfired on him, I snapped one day and was like, what am I doing? Why am I letting him control me? He's hurt me so many other times ... It was almost like, if I don't fight back, he's going to end up killing me" (Li et al, 2015, p.407-408).

In the second theme, who called the police and if there was prior police involvement, affected the arrest decision. With prior police involvement, when some women called the police, the police responded displaying irritability and even threatened to take the woman's child away if the woman called the police another time. 
For the third theme, the authors found that "arrest decisions often reflect a limited understanding of the context of the conflict and impact women's use of law enforcement in the future" (Li et al, 2015, p.411).In the fourth theme identified, the negative consequences described how women lost faith in the law and either decreased or stopped their use of law enforcement for domestic violence incidents. The positive consequences of arrest outlined by women described how their arrest experience gave them motivation and a new perspective that helped them leave their relationships.

The findings are largely diverse experiences and although very informative it is not conclusive. Limitations include the sample size which was only 18 women. The other weakness of the study is bias since the interviews are self-reports and of incidents that participants must call upon their own memory to recount.

In When women tell: Intimate partner violence and the factors related to police notification by Novisky and Peralta, the authors propose three hypotheses. First, if victim support for mandatory arrest increases, then reporting levels of intimate partner violence will also increase. The second hypothesis is, if children are involved, then intimate partner violence is more likely to be reported to law enforcement. Lastly, the third hypothesis is if alcohol or drug use by the abuser is present at the time of intimate partner violence victimization, then the probability of contacting police will increase (Novisky \& Peralta, 2015, p.69).

Qualitative data was collected via face to face interviews led by a survey during a period of nine months. Limitations of this study include generalizability, inability to draw causal relationships, small sample size, the fact that victims may already have a perceived notion of the police due to prior contact, etc.

For hypothesis number one, mandatory arrests were positively and significantly associated with reporting intimate partner violence. Regarding hypothesis number two, no significant relationship was found with children in the home and contacting police for intimate partner violence situations. For the 
third hypothesis, when an abuser was using drugs or alcohol during the time of abuse, the likelihood of reporting abuse to law enforcement increased by $65 \%$. The authors did not collect on the ages of children in the home and were unable to determine if the lack of significance between children in the home and reporting intimate partner violence was due to the ages of the children in any way (Novisky \& Peralta, 2015, p.79).

In Stereotype threat and racial differences in citizens' experiences of police encounters by Najdowski, Bottoms, and Goff, the authors want to know how stereotypes contribute to biased based policing and racial disparities. They want to know if Blacks really do experience stereotype threat in criminal justice encounters (Najdowski, Bottoms and Goff, 2015, p.464). They conducted two studies to answer the question: Do police encounters create stereotype threat? The authors compared the psychological experiences of Blacks and Whites to find out if any differences existed. The first study was done with self-reports. The second study asked participants to imagine a specific encounter with police. They predicted that Blacks (not Whites) would report being affected by the stereotype threat in law enforcement encounters.

Quote: "To our knowledge, this research is the first to empirically evaluate how stereotype threat might affect Blacks in situations in which interpersonal interactions can influence justice relevant outcomes" (Najdowski, Bottoms, and Goff, 2015, p.464). The focus here is police encounters and the psychological experiences of police encounters.

The participants in the research had an average age of 19 years old. There were 49 Black males and 184 White males. The participants were undergraduate students in psychology at the University of Illinois at Chicago. An Explicit Stereotype Threat scale was used for measurement. A seven point scale ranging from negative three to positive three. Negative three operationalized as strongly disagree and positive three as strongly agree. The findings showed that Blacks were significantly more likely to agree that they experience stereotype threat in police encounters versus Whites (Najdowski, Bottoms, and Goff, 
2015, p.465). More specifically, Black men reported concerns of being treated unfairly by police officers and stereotyped as criminals. Whereas White men, White women and Black women did not. The researchers operationalized 'stereotype threat' as: "Stereotype threat is the concern one experiences when at risk of being perceived in light of a negative stereotype that applies to one's group" (Najdowski, Bottoms, and Goff, 2015, p.464). Limitations include abstract questions about how participants would feel in certain police interactions where the police officer would be in close proximity to the participant. Are Latinas who report less confidence in police less likely to report that they were victims of violent crime? Messing et al explore this question in their article titled: Latinas' Perceptions of Law Enforcement: Fear of Deportation, Crime Reporting, and Trust in the System. The researchers focus is to find out if Latinas who report the fear of deportation by police will also report less confidence in police treatment.

The data in this article comes from the Pew Hispanic Center (2008). Interviews were sent out via landline/cell phone by random digit dialing. Interviews were conducted in either Spanish or English. One of the limitations in the study is that researchers were unable to compare the country of origin for respondents. A strength in the study is the assessment of the fear of deportation for the respondent and their loved ones. This enabled measurement for women's concern of their family members. A weakness found in the study is that the research reports on perceptions and not actual behaviors.

The findings showed an increase in education showed that Latinas had more confidence that the police would not use excessive force and that the courts would treat them fairly. They found that the fear of deportation was a significant indicator of Latina perception on the procedural justice system. They also found that the relationship between the fear of being deported and willingness to report violent crime, was no longer found when factoring in Latinas' confidence of no excessive force used by police. 
The next article in this literature review is Departmental professionalism and its impact on indicators of violence in police-citizen encounters by Shjarback and White. In this article, the researchers' goal is to analyze police professionalism in police-citizen encounters. The authors examine police professionalism with five different measures across 526 police agencies. The components measured include the importance of education in each agency, how many hiring standards or screening mechanisms the agency has, the number of required training hours, representation of females and the importance of community policing. The authors aim to examine the impact police professionalism has on violent outcomes with citizens.

The data for this study comes from the 2003 Law Enforcement Management and Administrative Statistics (LEMAS) survey. The authors also examine data from the FBI's 2003 Uniform Crime Report. The findings show a significant relationship between the department's education requirement and policecitizen violence. Higher education levels correlated with lower rates of police-citizen violence. Hiring standards, training standards, and community policing activities were not correlated with indicators of police-citizen violence.

This study has a great sample size. One of the limitations to this study, is that there is no national database that collects data on police-citizen violence across police agencies. There are additional factors that the authors could not control for or factor in such as the education level. Education levels were only measured at the entry level when police officers entered the agency. Education levels were not reevaluated during the officers' time of employment. Therefore, if an officer furthered their education during the time of their employment, it was not documented anywhere or factored into the study.

In the article, Why Are Some Officers More Supportive of Community Policing with Minorities than Others? by Kearns three hypotheses are explored to better understand why some officers are more supportive of community policing compared to other officers. The first hypothesis is; if police officers engage in more community policing practices, then they will have more positive views towards this 
policing style with minorities. The second hypothesis predicts that officers with a supportive attitude towards community policing will have positive views on community policing with minorities. The third hypothesis predicts police officers with a perception of social distance between them and minority communities will have a more negative view towards the minority group in community-oriented policing.

The data in this research comes from three police departments in Washington D.C. 742 officers from all three departments were given the opportunity to participate. 713 officers completed surveys and the other 28 either declined to participate or left surveys incomplete.

Self-reports from the officers are hard to generalize and there was concern for honesty from the officer regarding sensitive topics in the workplace. The study only looked at one location in the United States specifically in Washington D.C. which is considered by some as an area with a higher political atmosphere compared to other cities. Officer attitudes towards minorities will vary from location to location. The strength is in the number of officers that participated; made for a good sample size for the scope of the study. When compared to more than just one state the scope is small.

Officers were found to be more supportive of community policing in white communities versus non-white communities. Across all three departments, officers reported social distance from minorities. Hypothesis number one was not supported whereas hypothesis number two and there were.

In Policing roulette: Sex workers' perception of encounters with police officers in the indoor and outdoor sector in England by Klambauer, the author asks the following questions: What are the differences in indoor and outdoor sex workers' perception of encounters with police? How do these differences contribute to the literature? A qualitative study including 49 participants was conducted from September 2015 to March 2016. The data for this study was collected through semi-structured interviews. The research focuses on sex work in England and Wales. The methods used in this study are self-reports and interviews. The weakness for these data gathering methods is that the qualitative data 
is not empirical evidence. Self-reports and interviews have bias, personal opinions and various levels of interpretation. However, they do provide great insight. The interviews were between 15 and 120 minutes with an average time of 45 minutes. Four men, one transgender person and 44 women were interviewed.

The findings in this study showed both indoor and outdoor sex workers ... "interpreted their experiences with police, through the lens of their stigmatized status and did not expect respectful treatment" (Klambauer, 2017, p.257). Street based sex workers perceived their encounters with police more negative than indoor sex workers (Klambauer, 2017, p.257). Even when their encounters were considered positive, both indoor and outdoor sex workers were surprised when police helped or responded positively (Klambauer, 2017, p.258). "Indoor sex workers have a far more positive view of police than outdoor sex workers" (Klambauer, 2017, p.260). "When police officers expressed a better understanding of the work, the encounter was described as positive" (Klambauer, 2017, p. 262). Sex worker's stigma consciousness was a dominant theme in explaining negative, positive and nonresponsive experiences with police.

The article Community policing in racialized communities: A potential role for police social work by Giwa focuses on community policing. Giwa doesn't seem to favor the community-oriented policing strategy and community policing is described here as a failed promise. The author suggests that community policing is near an end and argues that police social workers are needed to improve relations with racialized communities. Author argues that police social workers are necessary to provide bias free policing. Giwa also references the case of Abdirahman Abdi in Ottawa and goes in depth about his death. The author utilizes the facts of Abdi's case to show that there are gaps in skills needed for community-police relations. Giwa argues that hired police social workers will fill the gap. The study by Lamin and Teboh (2016) that analyzes police working with social services in the community instead of hiring them is also referenced in this article. 
The author analyzes the Outreach Liaison Team (OLT) strategy that was created as a reaction to Abdi's death in the Somali community. The first problem found with this program/strategy is that most of the officers chosen were black. This decision assumes that by assigning black officers to reach out to the Somali community, it would have a positive effect and that those officers could do more for the community versus others. Another problem is having the OLT officers appear to have more decisionmaking power when authority to make changes within the department lies with upper management. The third problem with the strategy is that, like others, it was reactionary and only took place after a tragic event.

On page 720 , the author indicates that the scope of the paper is limited to and not on "How many police social workers are hired by different police organizations, under whose command they fall, and currently any jurisdiction where they have been innovatively used, are questions beyond the scope of this paper." The author also states that the paper is limited in a way that overlooks the depth of skills that social workers have. Giwa's article focuses on policing practices and strategies in Canada. The article claims appear reaching and no findings on this article cited anywhere.

In Structure and function: Impact on employment of women in law enforcement by Matusiak and Matusiak, the article's focus is to identify if there are still remnants of the traditional masculine hegemonic police structure. The authors want to know if there are limitations for the employment of women in police work. The data in this article comes from the LEMAS survey and the Federal Bureau of Investigation's Uniform Crime Report. The LEMAS survey is completed periodically in the United States and "All agencies that employ 100 or more sworn officers are solicited to participate as well as a nationally representative sample of smaller agencies" (Matusiak and Matusiak, 2018, p.318). There are data limitations that didn't allow for analysis across all small agencies. There are also inconsistencies across the nine waves of LEMAS surveys regarding the wording of questions and operationalization of variables. The author conducted an analysis on each LEMAS survey individually before grouping in order 
to mitigate inconsistencies. To get rid of inconsistencies across the LEMAS survey, the author suggests making them uniform.

The findings: Community-oriented policing and community engagement was found as a predictor of female sworn officers (Matusiak and Matusiak, 2018, p. 325). "Education requirements were found as a consistent predictor of higher levels of employment for female sworn officers" (Matusiak and Matusiak, 2018, p. 329). “Nonphysical requirements were not found as an impediment on the employment of female sworn officers" (Matusiak and Matusiak, 2018, p.329). Not much support in length of training time influencing women employment in the organization.

The authors believe that "greater inclusion of women is an admirable goal because representation in a police agency that mirrors the community which it polices leads to greater perceptions of legitimacy" (Matusiak and Matusiak, 2018, p.314). The researchers argue that encouraging employment diversity cannot end at the recruitment level and must be pushed through into employment retention. That police agencies must follow through with their desire to have a diverse workforce. The researchers argue that the policing culture must change for diversity to thrive in agencies and the way to attack this problem is through higher education levels. This article is important for the discussion around police contact with women. Having a police population that is similar to the community the officers are serving, may have a positive impact on encounters with women in the community.

In Rape victim advocates experiences with law enforcement in the emergency room by Long, the author aims to provide insight on rape victim advocates' perception of law enforcement interactions with rape victims. Interviews were conducted with 23 female victim advocates: "23 interviews with medical female advocates from one rape crisis center" (Long, 2018, p.502). The interviews went from 45 minutes to two hours. 
The researcher acknowledges that they were a medical advocate for a year and their experience has influenced their perception of the victim advocate interviews. Furthermore, the researcher recognizes, in the article, that they were a medical advocate for the medical center at which the research was conducted. The researcher acknowledged that they had an interaction with one out of the 23 interviewees prior to the research and was able to build rapport with the interviewees with his prior experience working there (Long, 2018, p.503).

The researcher found mixed results in this study. 14 advocates reported positive experiences with law enforcement contact in the emergency room. 17 out of the 23 advocates reported negative experiences with the law enforcement contact. Advocates recalled positive experiences with officers in their 50s and 60s who were fathers and or grandfathers. They also described positive experiences with women officers. Advocates also found that officers would confide in them and tell them stories of incidents they experienced on the job. Advocates seemed to interpret this as the officers needing their own counseling (Long, 2018, p.507). The author writes that officers may take the opportunity to talk to advocates about their own issues since the advocate is someone outside of the police department that they are likely to not encounter again. Negative experiences: "One of the main complaints against police officers by advocates is the lack of com- passion and their demeanor when engaging both advocate and survivor in the ER. This includes body language that suggests disinterest, using intimidation, rushing the survivor, and not believing the victim (Rich \& Seffrin, 2013)" (Long, 2018, p.507). Negative experiences described by rape victim advocates included encounters were the officer called picked up on the advocates and in one instance even asked an advocate out for a date. Some advocates complained about their experiences with officers in the ER stating that the officers were not aware of the subtle behaviors they exhibited that made victims feel uncomfortable and/or reluctant to give their statement. Other advocates described their negative experiences with officers with a more sympathetic outlook. Advocates blamed job stressors of police officers as the reason for rushing through the process and lack 
of sensitivity. Other negative experiences included officer expressions that conveyed doubt in the victim.

"Ten of the 23 advocates experienced officers either blaming the victims and/or not believing them"

(Long, 2018, p.508).

\section{Discussion:}

Through this literature review, three major themes emerged: a continued discussion on the community-oriented policing style and its effectiveness, women's perspectives on police and their encounters with police, and the analyzing of police behaviors in citizen encounters.

In the first five articles, researchers comment on the fact that there is more discussion of how and what females contribute to the field of policing instead of focusing on whether females in policing can perform the job adequately compared to males. It seems the conversation and perspective of women in policing began to shift after community-oriented policing started becoming popular.

Before community-oriented policing started to really become integrated into police agencies, researchers such as Miller in 1998, suggest to not favor women's natural nurturing traits to move into a community policing style. As the discussion around this policing style progressed, researchers used officer attitudes towards women to predict their attitudes towards the community-oriented policing practice. Researchers such as Murray in 2006 further argued that community-oriented policing encourages information sharing between the community and police force. Which in turn leads to the prevention of crimes against women and children such as human trafficking.

In 2017, community-oriented policing is examined to find out why some police officers are more or less supportive of the policing style while additionally factoring in minorities. At this point in the discussion, researchers recognize that almost all police agencies are reporting the community-oriented policing style as implemented in their agency. However, the level of support of this practice by officers varies and researchers want to understand on a deeper level why there is such variation. In 2018, researcher Giwa contributes to the discussion of community-oriented policing with research suggesting 
social workers are needed to be successful in this policing style; a style that aims to repair relationships with communities who have lost trust in the police. Giwa believes there must be a mediator between the police and the community to effectively connect the two; that this connection is too complex for the two parties to do on their own.

Eight out of the twenty articles researched contain research around women's perspectives of the police and their encounters. The perspectives explored come from groups such as women as victims of domestic violence, women as prostitutes in the sex industry, women as members of the Latina community, women as rape victim advocates for other women, and women as victims of crimes in general.

The perspective of women victims of domestic violence on the police has been looked at early on by Coulter et al in 1999, suggesting more domestic violence training for police is needed to deal with domestic violence calls for help. The researchers request training for police to be taught how to leave their personal beliefs and/or opinions out of their service to victims due to their finding of women being less likely to report incidents of domestic violence in comparison to men.

The perspective of female prostitutes on policing has also been focused on by Williamson et al in 2007. The researchers also make claim to the need for additional research on police officer values and beliefs toward women involved in the sex working industry. This group of women is an addition to the theme of perspectives of police by women. In 2015 and 2017, women perspectives of police are evaluated again. In 2015, the perspective of Latinas on the police is analyzed and later the perspective of sex workers and their encounters with police. Studies with women and their perspectives of police based on encounters continues to be used in the discourse community. The self-reports and interviews provide great qualitative data and insight for what is happening on a ground level between women and police. 
Police behaviors with citizens is another recurring theme found amongst the articles selected in this literature review. The articles surrounding this topic tell us that additional data needs to be collected on police actions, responses and behaviors with citizens. In the articles from 2007 to 2009, we can see domestic violence being used as a situational circumstance for analyzing police behaviors with women. A challenge that emerges from researchers attempting to learn more about police behaviors, is categorizing police behaviors into action types that are measurable. Additional research is called for in the articles from 2007 to 2009 , due to lack of data gathered on police behaviors by police administrations such as de-escalation techniques for violent citizen encounters.

In 2016, violent citizen-encounters are focused on again, this time by Shjarback and White. The researchers encounter the same challenge as in other studies: there is no national database that collects data on police-citizen violence across agencies. Thus meaning, there is a lack of data to work with. Also, officer levels of education were only recorded at time of entry and not reevaluated during the officer's time of employment. This impacts the study immensely by having no way to tell if officers furthered their education during time of employment. The lack of pertinent data such as officer education level and officer techniques and behaviors make it extremely difficult to analyze encounters between police and women, i.e. any other group in general.

\section{Conclusion:}

Police officer support for women as a community is inconsistent and not yet fully established. Researchers have found the interactions between the police and women to be both negative and positive. There are no clearly defined roles or actions for police to provide support to women. Police have been found to use their discretion with women in communities such as the sex industry for both positive and negative interactions. 
There has been fluctuation in attitudes towards women in policing alongside the emergence and utilization of community-oriented policing. First, women in policing have been discriminated against by the historical masculinity of the profession. Then, with the emergence of the community-oriented policing style, women are viewed as having an advantage with the approach due to assumed nurturing traits and behaviors. More recently, the research has again shifted its attitude on women paired with the community-oriented policing style. Later research is suggesting that in order to effectively utilize this style of policing, skills in policing must not be gendered. Furthermore, attitudes towards women in policing have been used to predict officer attitudes towards community-oriented policing. Higher education levels in officers have been linked with a more positive and favorable attitude towards community-oriented policing extending to support for women.

There are some areas in the research that can be further explored to provide more insight into police encounters with women. Women as perpetrators of crime were not found as a subject group for research. The closest example of women as perpetrators is women in domestic violence and intimate partner violence situations. Women as sole actors of crime were not found in the literature. Women as victims is the most explored group in the research. Although, the research on women as victims and their interactions with police is limited to qualitative data. Women as guardians of perpetrators were not found within the literature examined. Support levels by police for women who have juveniles in the system or juveniles perpetrating crime is another interesting area that could be further explored.

Overall, the literature on police interactions with women appears underdeveloped and the single most contributing obstacle is the lack of data collected by police administrations on their officers. 


\section{References}

Giacomazzi, A. L., \& Smithey, M. (2001). Community policing and family violence against women: lessons learned from a multiagency collaborative. Police quarterly, 4(1), 99-122.

Giwa, S. (2018). Community policing in racialized communities: A potential role for police social work. Journal of Human Behavior in the Social Environment, 28:6, 710-730. doi: $10.1080 / 10911359.2018 .1456998$

Jackson, D. TED Talks. (2016, May, 12). Problem-Oriented Policing: Where Social Work Meets Law Enforcement [Video file]. Retrieved from https://youtu.be/wK8gIFZuQw8

Murray, J. (2006). Criminal exploitation of women and children and the important role of community policing. Police Practice and Research, 7(02), 125-134. doi: 10.1080/15614260600676791

Problem-Oriented Policing. (n.d.). Retrieved March 9, 2019, from https://www.crimesolutions.gov/PracticeDetails.aspx?ID=32 


\section{Annotated Bibliography}

Annotations:

Miller, S. L. (1998). Rocking the rank and file: Gender issues and community policing. Journal of Contemporary Criminal Justice, 14(2), 156-172. https://doi.org/10.1177/1043986298014002004

I. Summarize the author's main research question: How can policing be changed into a less masculine or para militaristic structure? How can the values of policing be changed into care, empathy, connection, etc.? Does officer gender matter? Or does it matter more that they integrate the ethics of care into policing more actively? What other officer characteristics besides gender can effectively increase community policing? Quote: “...the article explores how stereotypically feminine traits once used to exclude women's participation from patrol, or to separate the "real" crime fighters from the "office cops" have now been resurrected and elevated to the pinnacle of community policing agendas and practice" (p.158-159).

II. The data examined included Carol Gilligan's (1982) "different voice" approach \& work from Kathleen Daly (1989) and other studies/work from 1990s

III. Findings? This article mainly uses the work of others to support their ideas.

IV. Include strengths/weakness. Are there limitations? What is the scope of the research? Cited by 32 per google scholar.

Coulter, M. L., Kuehnle, K., Byers, R., \& Alfonso, M. (1999). Police-Reporting Behavior and Victim-Police Interactions as Described by Women in a Domestic Violence Shelter. Journal of Interpersonal Violence, 14(12), 1290-1298. https://doi.org/10.1177/088626099014012004

I. Summarize the author's main research question is to analyze "...the relationship between abuse characteristics and calls to the police" (Coulter, Kuehnle, Byers \& Alfonso, 1999, p.1291). The author's also examined victims' perceptions on the responses of police officers "to their calls for help" (Coulter, Kuehnle, Byers \& Alfonso, 1999, p.1291). 
II. What data was used? The data includes 500 questionnaires. Includes qualitative and quantitative data. The study was conducted in the largest shelter for domestic violence victims in the state of Florida. The questionnaires were given to women during the intake process at the shelter from June of 1995 to August of 1996.

III. What were the findings? The findings showed a significant relationship between abuse type and the victims' decision to call the police for help. The type of abuse that elicited a call for help to police was physical abuse. Significance between the victim and their relationship with their abuser was also found. Over $70 \%$ of victims called police for help, identified the perpetrator of abuse as their current partner. Additionally, significance was found in the relationship of the abuser to the victim and whether the abuser was arrested.

IV. Include strengths/weakness. Are there limitations? What is the scope of the research? Generalization of the findings is limited due to self-reports and sample/sample size. One of the strengths is the mix of both quantitative and qualitative data. Another weakness might be the timeframe that the data was collected from. Say might say that it is now outdated due to changes in domestic relationships and policing styles over time. The policing style in Florida during that time frame was not identified. This article was cited by 26.

Sims, B., Scarborough, K. E., \& Ahmad, J. (2003). The relationship between police officers' attitudes toward women and perceptions of police models. Police Quarterly, 6(3), 278-297. doi:

\section{$10.1177 / 1098611103254315$}

I. The author's main research question: In what ways can attitudes towards women predict attitudes towards community-oriented policing?

II. Data collected from surveys given to 560 sworn police officers at the Little Rock Police Department in the year 2000. 
III. Findings suggest that minority officers are more likely to believe that women in the United States still suffer from discrimination. Education had a little to no correlation on affecting the attitudes of officers towards community policing. Marital status influenced the attitudes towards women in the workplace. Officers that identified as married or in a relationship had more favorable attitudes towards women than the single officers. Another finding was that as time spent with female officers increased, the likelihood of having negative attitudes towards women decreased.

IV. Strengths/weakness: Limitations on generalizability due to survey research. The scope of the research is only on one agency in Little Rock Arkansas.

DeJong, C. (2005). Gender differences in officer attitude and behavior. Women \&amp; Criminal Justice, 15:3-4, 1-32. doi: 10.1300/J012v15n03_01

I. Summarize the author's main research question: Does citizen sex affect the way different genders of police respond? How do police officer attitudes affect police-citizen encounters? What are the attitudinal differences between male and female officers? Do these differences provide comfort or reassurance to citizens? Ultimately, the article focuses on the relationship between officer gender, attitude and behavior.

II. The data used for analyses came from the Project on Policing Neighborhoods (POPN). Observational data extracted from ride-alongs by trained observers and self-reports from surveys given to officers.

III. Findings: Female citizens were more likely to receive contact and comfort from female officers than makes. Both male and female officers were more likely to show comfort to female citizens than male citizens overall. Officer sex interacting with other variables such as education, citizen class, and race have significant effects on behavior. 
IV. Strengths/weakness: One of the limitations was that POPN was not designed to measure certain behaviors so there are varying explanations for the differences in behaviors measured. The author recognizes that there are differences in organizations and police departments. The author suggests additional research comparing more than just two police departments. Another limitation of the data is that the original study did not measure whether officers felt comfortable engaging in certain behaviors like comfort or coercion with citizens. This article was cited by 73.

Murray, J. (2006). Criminal exploitation of women and children and the important role of community policing. Police Practice and Research, 7(02), 125-134. doi: 10.1080/15614260600676791

I. The author's main argument is that if community policing diminishes in practice, then women and children victims will lose more rights and be criminally exploited more than they already are. The criminal exploitation the author covers is human trafficking. The author's concern is that if community policing perishes, then the traditional and more para militaristic model will fill the void.

II. The data used includes Australian Laws and policies on slavery and sexual servitude: Criminal Code Amendment (Slavery and Sexual Servitude) Act. Crimes Act 1914 and the Migration Act 1958.

III. Findings: Successful prosecutions for sex crimes and human trafficking rely heavily on information given to the police/investigations. Information sharing with the police is encouraged with a community policing style. This is not really a finding but a claim that the author makes. The author only describes Australian policy and practices and does not reference any evaluation of those laws.

IV. Strengths/weakness: This author cites himself/own work a lot. The scope is limited to human trafficking and sexual servitude and how the loss of community policing will negatively affect the 
victims of such crimes. The scope is also limited to Australia. This article was also only cited by 5 (may need to find a better article to replace this one).

Williamson, C., Baker, L., Jenkins, M. \& Cluse-Tolar, T. (2007). Police-Prostitute Interactions. Journal of Progressive Human Services, 18:2, 15-37. doi: 10.1300/J059v18n02_03

I. The author's main research question is to see what interactions prostitutes and police have had due to the amount of discretion police are given on the job. The author's aim is to identify police behaviors when interacting with prostitutes and the implications that those interactions may have for future social work.

II. What data was used? The data used in this article came from three studies on prostitution in the streets from 1998 to 2004 . The first study is comprised of qualitative interviews of ex-

prostitutes. The 21 women used in the first study were found using the snowball technique. The second study included a quantitative survey on police and prostitute interactions. The third study included qualitative interviews of a mix of women that were working as prostitutes at the time of the interview, those involved in recovery programs, and those not working as prostitutes at the time of the interview and not involved in any type of recovery program.

III. What were the findings? There is a lot of variety in police behavior with prostitutes. 6 types of interactions between police and prostitutes were found. The following are the categories of police behavior types found: "nice cops, non-responsive officers, police officers as protectors, police officers as perpetrators, cops as paying customers, and fringe benefit cops."

IV. Include strengths/weakness. Are there limitations? What is the scope of the research? Did someone criticize the work? Officer attitudes and demographics were not considered or examined in the study and the authors suggest further studies on those two components. There is also some strength in qualitative data in that it reveals details that numbers cannot show. 
Schuck, A. M., \& Rabe-Hemp, C. (2007). Women police: The use of force by and against female officers. Women \& Criminal Justice, 16(4), 91-117. doi: 10.1300/J012v16n04_05

I. Summarize the author's main research question: The authors' main research question is what the relationship of physical force with citizens by female officers is. The authors also look at force used against female officers and the effects of same sex and mixed sex pairings of officers on force. The authors have four hypotheses. The first is "...that female officers will use less force than their male counterparts" (Schuck \& Rabe-Hemp, 2007, p.96). The second hypothesis is that “...the effect of gender on police use of force should be significant when controlling for other confounding factors" (Schuck \& Rabe-Hemp, 2007, p.96). The third is that there will be lower rates of physical force towards citizens by female officers due to positive attitudes around females as officers (Schuck \& Rabe-Hemp, 2007, p.96). The last hypothesis is that there will be lower levels of physical force used against female officers during domestic calls because women are often seen as better at handling emotions and relations. (Schuck \& Rabe-Hemp, 2007, p.9697).

II. What data was used? Surveys were distributed to both male and female officers across six departments. Years that the data was gathered: 1996-1997. The sites that the data was collected from: "Charlotte, NC; Colorado Springs, CO; Dallas, TX; St. Petersburg, FL; San Diego Police, CA; and the San Diego Sheriff's Office" There were 7,512 surveys and only $10 \%$ were completed by female officers.

III. What were the findings? Female officers and female paired officers used less force in citizen interactions than their male counterparts. Female officers were also found to be less likely to use physical force during citizen interactions than male officers. However, citizens used significantly more force towards female officers than male officers during domestic service calls. 
IV. Include strengths/weakness. Are there limitations? There are some limitations in the work. The measures of evaluation were limited and there isn't necessarily empirical evidence that female officers are better at de escalating violent encounters with citizens. The authors suggest an entire study dedicated to de-escalation techniques and how they compare.

Sun, I. Y. (2007). Policing domestic violence: Does officer gender matter? Journal of Criminal Justice, 35(6), 581-595. doi:10.1016/j.jcrimjus.2007.09.004

I. The author's main research question: Do female police officers respond to domestic violence differently than male officers? Does officer gender matter when responding to domestic violence?

II. What data was used? The data used came from the Project on Policing Neighborhoods (POPN) in Indiana and Florida between the summers of (1996 \& 1997).

III. What were the findings? Female officers were more likely to provide support to domestic violence situations than male officers. Female and male officers don't differ in using control actions as well as in the most coercive actions such as arrests. Arrests were not made in most domestic violence responses.

IV. Include strengths/weakness. Limitations include limited action types by officers were included in previous research. Not very many action types/responses to work with or analyze. The data is limited to two agencies. Strengths of the research: Two approaches in analyzing. They use the SSO method and collected qualitative data from interviews.

Rabe-Hemp, C. E. (2008). Female officers and the ethic of care: Does officer gender impact police behaviors?. Journal of Criminal Justice, 36(5), 426-434. doi:10.1016/j.jcrimjus.2008.07.001

I. Summarize the author's main research question: The main part of the research question explores how officer gender impacts everyday police-citizen encounters and how it determines what behaviors are used by different genders in encounters and resolutions. Which gender is 
more likely to use extreme controlling behaviors? Which is more likely to use supporting behaviors? Which gender uses lower level behaviors more often and in what context?

II. The data used for analyses came from the Project on Policing Neighborhoods (POPN).

III. The findings were mixed. They showed that female officers were less likely to use controlling behaviors compared to male officers. However, the findings also showed that female officers were not more likely than male officers to use supporting behaviors. Female officers were 19 percent less likely to use supporting behaviors in police-citizen interactions than males. Research suggests that situational context, citizen demographics, officer demographics, organizational and legal factors also influence officer behaviors. Gender is not the only factor and is not weighed as heavily as one would think.

IV. Strengths/weakness: There is a limitation on numerical data for female officers therefore female officer interactions with citizens are underrepresented in the study analyzed. One of the strengths was categorizing police behaviors into meaningful categories making it easier to analyze with the small sample size. The research focuses on data from one study. There is quantitative data extracted from the original study. A weakness is that the data analyzed comes from a study done during the summers of 199 to 1997. It is hard to confirm that the data on behaviors is still completely relevant since social behaviors and political environments change over time.

Poteyeva, M., \& Sun, I. Y. (2009). Gender differences in police officers' attitudes: Assessing current empirical evidence. Journal of Criminal Justice, 37(5), 512-522.

doi:10.1016/j.jcrimjus.2009.07.011

I. The author's main research question: What does quantitative data say about how different or similar attitudinal differences between male and female officers are? The author focuses on analyzing empirical evidence to find the answer to this question. 
II. What data was used? Articles between 1990 and 2006 from U.S academic journals only. 27 Journals and 33 articles were extracted from those journals. Only articles that covered studies on U.S. police and police officers' own attitudes.

III. Number one was that the influence of officer gender on their attitudes of the police role remains inconclusive. The second finding is that there is very little support to show that females would embrace the community policing style better than their male counterparts because of their feminine nature/qualities. The third finding is that police attitudes towards the public improved with community-oriented policing. They also found that there is limited support of gender difference in job related stress for officers.

IV. Strengths/weakness: One limitation is that they did not include qualitative data such as interviews. Analyses were done on quantitative data only. Another limitation is that only 33 articles over a time period of 17 years was evaluated and does not account for some demographic and organizational changes.

Li, S., Levick, A., Eichman, A., \& Chang, J. C. (2015). Women's Perspectives on the Context of Violence and Role of Police in Their Intimate Partner Violence Arrest Experiences. Journal of Interpersonal Violence, 30(3), 400-419. doi: 10.1177/0886260514535100

I. Summarize the author's main research question: The authors' main research objective is to evaluate women's perspectives and experiences with arrest around intimate partner violence.

II. What data was used? The study included semi-structured qualitative interviews. Interviews were conducted on women who were court ordered to participate in education programs because of intimate partner violence. The women interviewed were women that attended education groups for intimate partner violence from 2009 to 2012. These women were at least 18 years of age and able to speak English. Participants had to be willing to talk freely about their arrest and violent experiences. 
III. What were the findings? There are themes and trends found in the reasons why women began using IPV or were a part of IPV. Many women adapted to using violence after being victims of chronic abuse and violence. Many women described being driven to use violence and thus adopted the idea that using violence resembles strength and a means of protecting oneself.

IV. Include strengths/weakness. Are there limitations? The findings are largely diverse experiences and although very informative it is not conclusive. Other limitations include the sample size which was only 18 women. The other weakness of the study is bias since the interviews are essentially self-reporting and of incidents that participants must call upon their own memory to recount.

Novisky, M. A., \& Peralta, R. L. (2015). When women tell: Intimate partner violence and the factors related to police notification. Violence against women, 21(1), 65-86. doi:

\section{$10.1177 / 1077801214564078$}

I. The authors propose three hypotheses: 1 . If victim support for mandatory arrest increases, then reporting levels of intimate partner violence will also increase. 2 . If children are involved, then intimate partner violence is more likely to be reported to law enforcement. 3. If alcohol or drug use by the abuser is present at the time of the intimate partner violence victimization, then the probability of contacting police will increase.

II. What data was used? Qualitative data was collected via face to face interviews led by a survey during a period of nine months.

III. What were the findings? For hypothesis number one, mandatory arrests were positively and significantly associated with reporting intimate partner violence. In regard to hypothesis number two, no significant relationship was found with children in the home and contacting police for intimate partner violence situations. For the third hypothesis, when an abuser was using drugs 
or alcohol during the time of abuse, the likelihood of reporting abuse to law enforcement increased by $65 \%$.

IV. Include strengths/weakness: The authors did not collect on the ages of children in the home and were unable to determine if the lack of significance between children in the home and reporting intimate partner violence was due to the ages of the children in any way. Page 79. Limitations include generalizability, inability to draw causal relationships, small sample size, the fact that victims may already have a perceived notion of the police due to prior contact, etc.

Najdowski, C. J., Bottoms, B. L., \& Goff, P. A. (2015). Stereotype threat and racial differences in citizens' experiences of police encounters. Law and human behavior, 39(5), 463. doi: 10.1037/lhb0000140

I. Summarize the author's main research question: How stereotypes contribute to biased based policing and racial disparities. They want to know if Blacks really do experience stereotype threat in criminal justice encounters p.464. They conducted two studies - do police encounters create stereotype threat? Compared the psychological experiences of Blacks and Whites to find the differences if any. Study 1: self-reports. Study 2: asked participants to imagine a specific encounter with police. They predicted that Blacks (not Whites) would report being affected by the stereotype threat in cj encounters.

Quote: "To our knowledge, this research is the first to empirically evaluate how stereotype threat might affect Blacks in situations in which interpersonal interactions can influence justice relevant outcomes" (p.464). The focus is police encounters and the psychological experiences of police encounters.

II. What data was used? Self-reports - The first study was done with self-reports. The second study asked participants to imagine a specific encounter with police.

III. What were the findings? The findings showed that Blacks were significantly more likely to agree that they experience stereotype threat in police encounters versus Whites (Najdowski, Bottoms, 
and Goff, 2015, p.465). More specifically, Black men reported concerns of being treated unfairly by police officers and stereotyped as criminals. Whereas White men, White women and Black women did not.

IV. Include strengths/weakness. Are there limitations? What is the scope of the research? Did someone criticize the work? They operationalized 'stereotype threat' as: "Stereotype threat is the concern one experiences when at risk of being perceived in light of a negative stereotype that applies to one's group" p.464

Messing, J.T., Becerra, D., Ward-Lasher, A. \& Androff, D.K. (2015). Latinas' Perceptions of Law Enforcement: Fear of Deportation, Crime Reporting, and Trust in the System. Journal of Women and Social Work, 30(3), 328-340. doi: 10.1177/0886109915576520

I. The author's main research question: To find out if Latinas who report the fear of deportation by police will also report less confidence in police treatment. Are Latinas who report less confidence in police less likely to report that they were victims of violent crime?

II. The data used was from the Pew Hispanic Center (2008). Interviews that were sent out via landline/cell phone by random digit dialing. Interviews were conducted in either Spanish or English.

III. What were the findings? An increase in education showed that Latinas had more confidence that the police would not use excessive force and that the courts would treat them fairly. They found that the fear of deportation was a significant indicator of Latina perception on the procedural justice system. They also found that the relationship between the fear of being deported and willingness to report violent crime, was no longer found when factoring in Latinas' confidence of no excessive force used by police.

IV. Strengths/weakness: One of the limitations was that they were unable to compare the country of origin for respondents. One of the strengths was the assessment of the fear of deportation 
for the respondent and their loved ones. This enabled measurement for women's concern of their family members. One of the weaknesses is that the research reports on perceptions and not actual behaviors.

Shjarback, J. A., \& White, M. D. (2016). Departmental professionalism and its impact on indicators of violence in police-citizen encounters. Police quarterly, 19(1), 32-62. https://doi.org/10.1177/1098611115604449

I. The author's main research goal is to analyze police professionalism in police-citizen encounters. The authors examine police professionalism with five different measures across 526 police agencies. The component ts measured include the importance of education in each agency, how many hiring standards or screening mechanisms the agency has, the number of required training hours, representation of females and the importance of community policing. The authors aim to examine the impact police professionalism has on violent outcomes with citizens.

II. What data was used? Data was used from the 2003 Law Enforcement Management and Administrative Statistics (LEMAS) survey. The authors also examine data from the FBI's 2003 Uniform Crime Report.

III. What were the findings? The findings show a significant relationship between the department's education requirement and police-citizen violence. Higher education levels correlated with lower rates of police-citizen violence. Hiring standards, training standards, and community policing activities were not correlated with indicators of police-citizen violence.

IV. Include strengths/weakness. Are there limitations? What is the scope of the research? Great sample size. One of the limitations is that there is no national database that collects data on police-citizen violence across police agencies. There are additional factors that the authors could not control for or factor in such as the education level. Education level was only measured at the 
entry level when police officers entered the agency and not after when there is potential that officers could further their education while employed.

Kearns, E.M. (2017). Why Are Some Officers More Supportive of Community Policing with Minorities than Others? Justice Quarterly, 34:7, 1213-1245. doi: 10.1080/07418825.2017.1380837

I. Summarize the author's main research question: The first hypothesis is that if police officers engage in more community policing practices, then they will have more positive views towards this policing style with minorities. Hypothesis two: Officers with a supportive attitude towards community policing will have positive views on community policing with minorities. The third hypothesis is that police officers with a perception of social distance between them and minority communities will have a more negative view towards the minority group in communityoriented policing.

II. What data was used? Data came from three police departments in Washington D.C. 742 officers from all three departments were given the opportunity to participate. 713 officers completed surveys and the other 28 either declined to participate or left surveys incomplete.

III. What were the findings? Officers were found to be more supportive of community policing in white communities versus non-white communities. Across all three departments, officers reported social distance from minorities. Hypothesis number one was not supported whereas hypothesis number two and there were.

IV. Include strengths/weakness. Are there limitations? Self-reports from the officer are hard to generalize. There was concern for honesty from the officer regarding sensitive topics in the workplace. The study only looked at one location in the United States specifically in Washington D.C. which is considered by some as being in a more political atmosphere. Officer attitudes towards minorities will vary from location to location. The strength is in the number of officers 
that participated; made for a good sample size for the scope of the study. When compared to more than just one state the scope is small.

Klambauer, E. (2018). Policing roulette: Sex workers' perception of encounters with police officers in the indoor and outdoor sector in England. Criminology \& Criminal Justice, 18(3), 255-272.

I. Main research question: What are the differences in indoor and outdoor sex workers' perception of encounters with police? How do these differences contribute to the literature?

II. What data was used or gathered? A qualitative study including 49 participants. Conducted from September 2015 to March 2016. Semi-structured interviews.

III. What were the findings? Both indoor and outdoor sex workers ... "interpreted their experiences with police, through the lens of their stigmatized status and did not expect respectful treatment" (p.257). Street based sex workers perceived their encounters with police more negative than indoor sex workers (p.257). Even when their encounters were considered positive, both indoor and outdoor sex workers were surprised when police helped or responded positively (p.258). Interviews between 15 and 120 minutes with an average time of 45 minutes. Four men, one transgender person and 44 women were interviewed. "Indoor sex workers have a far more positive view of police than outdoor sex workers" (p.260). "When police officers expressed a better understanding of the work, the encounter was described as positive" ( $p$. 262). Sex worker's stigma consciousness was a dominant theme in explaining negative, positive and non-responsive experiences with police.

IV. Strengths/weaknesses? Self-reports/interviews. Qualitative data is not necessarily empirical evidence but provides great insight.

V. Additional notes: Cited by 6 per google scholar. Focused on sex work in England and Wales. Sex work legal in England and Wales. 
Giwa, S. (2018). Community policing in racialized communities: A potential role for police social work. Journal of Human Behavior in the Social Environment, 28:6, 710-730. doi:

$10.1080 / 10911359.2018 .1456998$

I. The author's main research question is on community policing. The author doesn't seem to favor the community policing strategy. Community policing is described here as a failed promise. The author suggests that community policing is near an end and argues that police social workers are needed to improve relations with racialized communities. Author argues that police social workers are necessary to provide bias free policing.

II. The author references the case of Abdirahman Abdi in Ottawa and goes in depth about his death. Uses Abdi's case to show that there are gaps in skills needed for community-police relations. Argues that hired police social workers will fill the gap. Also references study by Lamin and Teboh (2016) that analyzes police working with social services in the community instead of hiring them.

III. What were the findings? The author analyzes the Outreach Liaison Team (OLT) strategy that was created as a reaction to Abdi's death in the Somali community. The first problem found with this program/strategy is that most of the officers chosen were black. This decision assumes that by assigning black officers to reach out to the Somali community, it would have a positive effect and that those officers could do more for the community versus others. Another problem is having the OLT officers appear to have more decision-making power when authority to make changes within the department lies with upper management. The third problem with the strategy is that, like others, it was reactionary and only took place after a tragic event

IV. Strengths/weakness: On page 720, the researcher indicates that the scope of the paper is limited to and not on "How many police social workers are hired by different police organizations, under whose command they fall, and currently any jurisdictions where they have 
been innovatively used, are questions beyond the scope of this paper." The author also states that the paper is limited in a way that overlooks the depth of skills social workers have. What is the scope of the research? Did someone criticize the work? This article focuses on policing practices and strategies in Canada. The article claims appear reaching and no findings on this article cited anywhere.

Matusiak, R. E., \& Matusiak, M. C. (2018). Structure and function: Impact on employment of women in law enforcement. Women \& Criminal Justice, 28(4), 313-335. doi:

\section{$10.1080 / 08974454.2018 .1454876$}

I. Summarize the author's main research question: The main focus is to identify if there are still remnants of the traditional masculine hegemonic police structure. Are there limitations for the employment of women in police work?

II. The data used came from the LEMAS survey and the Federal Bureau of Investigation's Uniform Crime Report.

III. Findings: “Community-oriented policing and community engagement was found as a predictor of female sworn officers. Education requirements found as a consistent predictor of higher levels of employment for female sworn officers. Non physical requirements were not found as an impediment on the employment of female sworn officers. Not much support in length of training time influencing women employment in the organization" (Matusiak and Matusiak, 2018, p.329).

IV. Strengths/weakness: There were data limitations that didn't allow for analysis across all small agencies. There are also inconsistencies across the nine waves of LEMAS surveys with the wording of questions and operationalization of variables. The author conducted an analysis on each LEMAS survey individually before grouping in order to mitigate inconsistencies. To get rid of inconsistencies across the LEMAS surveys, the author suggests making them uniform. 
Long, L. M. (2018). Rape victim advocates experiences with law enforcement in the emergency room. Feminist Criminology, 13(5), 498-515. doi: 10.1177/1557085116687033

I. Main research question/focus: Focus is to provide insight on rape victim advocates' perception of law enforcement interactions with rape victims. Interviews were conducted with 23 female victim advocates.

II. Methods: Qualitative interviews. "23 interviews with medical female advocates from one rape crisis center" (p.502). Interviews went from 45 minutes to 2 hours.

III. Findings: The researcher found mixed results. 14 advocates reported positive experiences with LE contact in the ER. 17 out of the 23 advocates reported negative experiences with LE. Advocates recalled positive experiences with officers in their 50 s and 60 s who were fathers and or grandfathers. They also described positive experiences with women officers. Advocates also found that officers would confide in them and tell them stories of incidents they experienced on the job. Advocates seemed to interpret this as the officers needing their own counseling. The author writes that officers may take the opportunity to talk to advocates about their own issues since the advocate is someone outside of the police department that they are likely to not encounter again. Negative experiences: "One of the main complaints against police officers by advocates is the lack of com- passion and their demeanor when engaging both advocate and survivor in the ER. This includes body language that suggests disinterest, using intimidation, rushing the survivor, and not believing the victim (Rich \& Seffrin, 2013)" (Long, 2018, p.507). A quote of a quote. Negative experiences described by rape victim advocates included encounters were the officer called picked up on the advocates and in one instance even asked an advocate out for a date. Some advocates complained about their experiences with officers in the ER stating that the officers were not aware of the subtle behaviors they exhibited that made victims feel uncomfortable and/or 
reluctant to give their statement. Other advocates described their negative experiences with officers with a more sympathetic outlook. Advocates blamed job stressors of police officers as the reason for rushing through the process and lack of sensitivity. Other negative experiences included officer expressions that conveyed doubt in the victim. "Ten of the 23 advocates experienced officers either blaming the victims and/or not believing them" (Long, 2018, p.508).

IV. Strengths/weaknesses: The researcher acknowledges that he was a medical advocate for a year and his experience may have influenced his perception of the interviews. Furthermore, the researcher recognized that he was a medical advocate for the medical center at which he was conducting the research. The researcher acknowledged that he had an interaction with one out of the 23 interviewees and was able to build rapport with the interviewees with his prior experience working there (Long, 2018, p.503). 